Geografia e Ordenamento do Território, Revista Electrónica

Centro de Estudos de Geografia e Ordenamento do Território

http://cegot.org

ISSN : 2182-1267

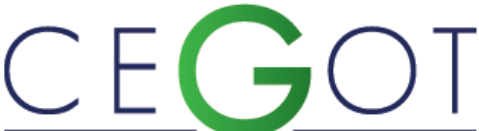

Centro de Estudos de Geografia e Ordenamento do Território
Celestino, Vivian

Departamento de Engenharia Ambiental e Fundiária Eletrosul Eletrobras Centro Interdisciplinar de Ciências Sociais (CICS.NOVA) / Universidade Nova de Lisboa

Rua Deputado Antônio Edu Vieira, 999, Bairro Pantanal, Florianópolis/SC CEP 88040-901, Florianópolis, Brasil viviancart@yahoo.com.br

\title{
Estimativa de alcance visual humano aplicado à preservação de ambientes cênicos
}

\author{
Estimate of human visual range applied to the preservation of scenic \\ environments
}

Referência: Celestino, Vivian (2017). Estimativa de alcance visual humano aplicado à preservação de ambientes cênicos. Revista de Geografia e Ordenamento do Território (GOT), n.o 11 (junho). Centro de Estudos de Geografia e Ordenamento do Território, p. 99-123, dx.doi.org/10.17127/got/2017.11.005

\section{RESUMO}

O Caminho das Tropas são estruturas remanescentes de importantes vias terrestres construídas na região da Coxilha Rica/Brasil. O objectivo principal deste trabalho é calcular a acuidade visual linear e logarítmica humana a visar à geração de poligonais de visibilidade para preservação do ambiente cênico da Coxilha Rica. O método proposto consistiu em calcular, com base em abordagens científicas diferentes, a relação entre a acuidade visual humana, a curvatura terrestre e a refração atmosférica e verificar como elas influenciam o alcance visual percebido pelo homem no ambiente. Com base nos resultados foram delimitadas as áreas onde ocorreriam as intervenções futuras na paisagem, a visar a minimização dos impacte(s) ambientais e visuais dos aspetos históricos e arqueológicos inerentes a região estudada.

Palavras-chave: Acuidade Visual Humana, Poligonais de Visibilidade, Caminho das Tropas, Alcance Visual Humano.

\section{ABSTRACT}

The "Caminho das Tropas", the "Cattle Drive Routes", are remaining structures of important cattle drive routes built in the "Coxilha Rica/Brasil" region. The main objective of the given 
studies is to calculate the human linear and logarithmic visual perceptiveness, aiming at the generation of visibility polygonals for the preservation of the scenic environment of the "Coxilha Rica". The method proposed includes the calculation, based on the different scientific approaches applied, the relationship between the human visual perceptiveness, the earth's curvature and the atmospheric refraction and the verification of how these elements influence the visual reach, perceived by man, in the environment. Based on the results, the regions were defined in which future activities might affect the given countryside, aiming at the minimization of their resulting environmental impacts, mainly concerning their visual aspects, on the historical and the archaeological elements encountered in the region here studied.

KeyWords: Human Visual Perceptiveness, Visibility Polygonals, Cattle-Drive Routes

\section{Introdução}

Na época do Brasil Colônia, especificamente, na primeira metade do século XVIII, importantes vias terrestres foram construídas, sendo utilizadas até meados do século $X X$. $A$ finalidade das vias era promover o transporte e o comércio de tropas de muares e bovinos para abastecimento da região das minas de ouro e ligavam o Rio Grande do Sul à Sorocaba (São Paulo), atravessavam os Campos de Lages em Santa Catarina/Brasil... A este período de manifestação cultural, com encontro de diferentes costumes e atividades económicas, foi atribuído o termo Tropeirismo (ABATI ET AL, 2010).

Remanescentes históricos e culturais desse período estão presentes por toda uma região denominada Coxilha Rica, e devido a sua peculiaridade, o Instituto de Patrimônio Histórico e Artístico Nacional (IPHAN) demonstrou preocupação com a preservação desses elementos na região, não somente pelo seu potencial turístico, suas fazendas históricas, antigos corredores de taipas, gastronomia, seus campos cavalgáveis, mas também por seu destacado potencial hidrológico.

A Coxilha Rica situa-se no município de Lages, no Estado de Santa Catarina/Brasil, ocupa pouco mais de $800 \mathrm{~km}^{2}$ de área, o que corresponde a $40 \%$ do território municipal. Destacase por sua beleza natural e seu rico patrimônio arquitetônico (ABATI ET AL, 2010). Ver área de abrangência da Coxilha Rica na figura 01. 


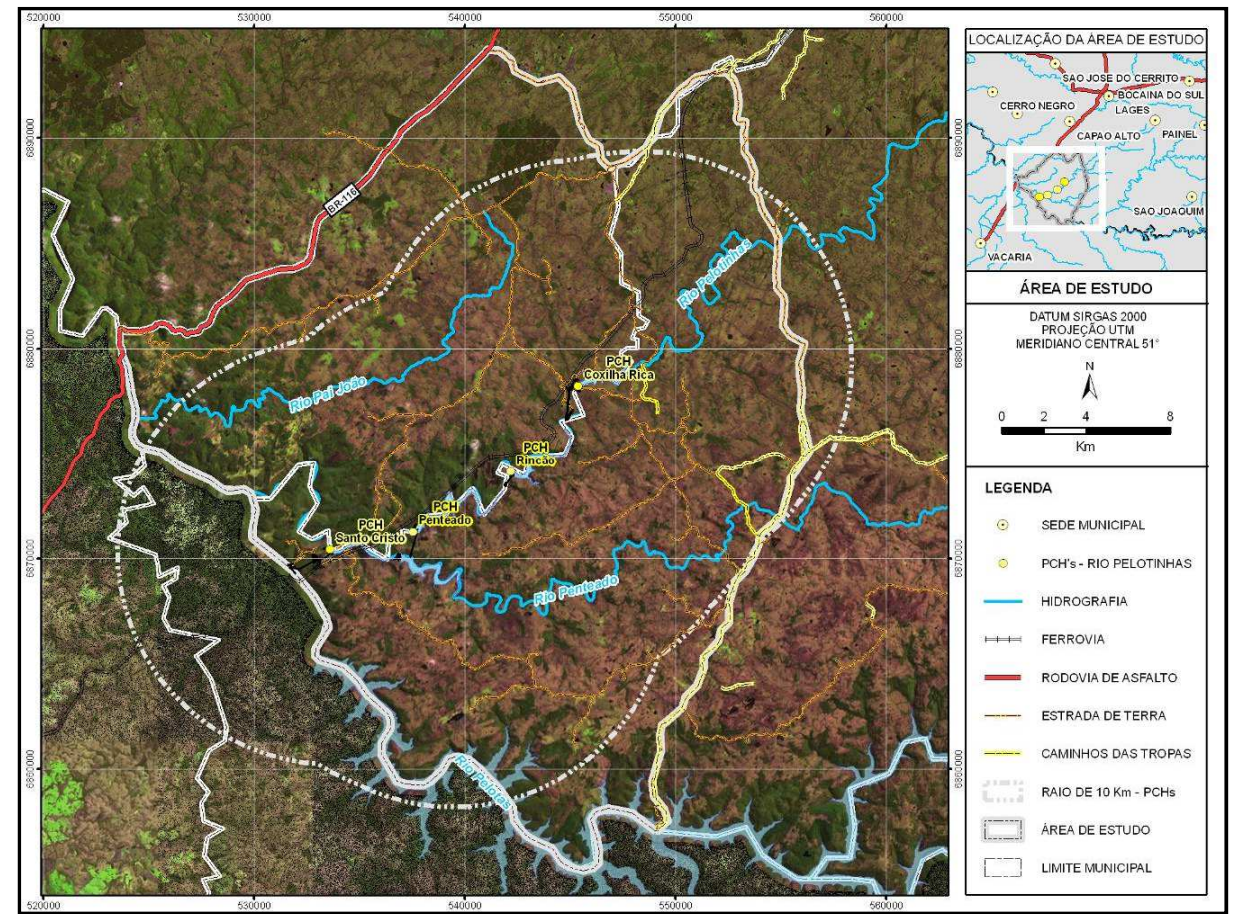

Figura 01 - Área de abrangência da Coxilha Rica Fonte: Abati et al (2010)

De acordo com Herberts (2009) e Abati et al (2010), através da Coxilha Rica atravessavam importantes rotas de transporte terrestre, denominadas "Caminhos das Tropas", construídas pela coroa portuguesa com diferentes objectivos, como:

1) prevenir o ataque espanhol e suas incursões permanentes no território português;

2) povoar o interior do território, visando à expansão das fronteiras portuguesas;

3) ligar o interior do Brasil Colônia às principais vilas do império, promovendo a integração económica e o intercâmbio cultural;

4) promover a comunicação terrestre entre as Capitanias;

5) estabelecer um caminho fixo e seguro para o transporte das tropas e mercadorias que abasteciam o mercado interno.

O solo da Coxilha era pedregoso, na maior parte formada por pedras de basalto. Então, para maior segurança e menor impacte na viagem das tropas, os caminhos foram despedrados e o basalto retirado do solo serviu como matéria-prima para a construção dos denominados "corredores de taipa", que se constituíam, basicamente, em muros de pedra intatos, 
encaixados hermeticamente sem a necessidade de qualquer tipo de argamassa. Os corredores também serviram para delimitar o caminho a ser percorrido pelos animais (HERBERTS, 2009). Ver a configuração dos corredores de taipas nas figuras 02a e 02b.
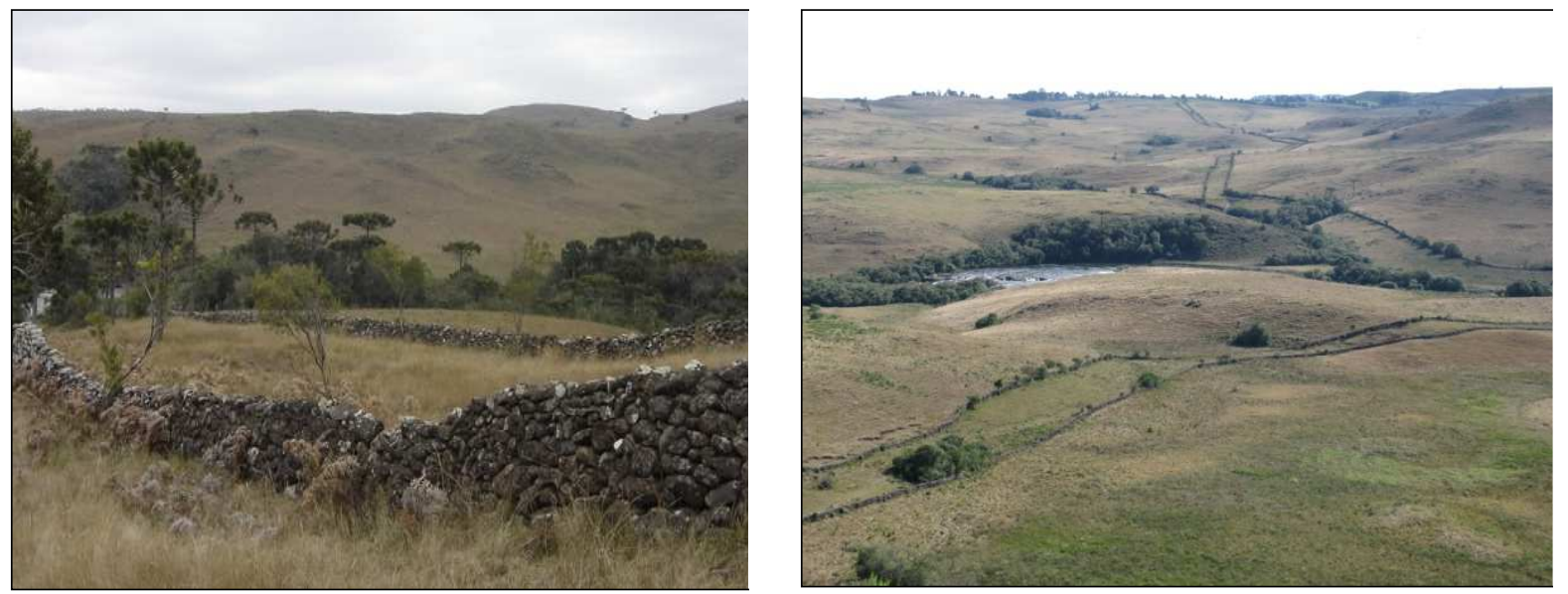

Figuras 02a e 02b - Corredores de taipas (muros de pedras)

Fonte: Abati et al (2010)

$\mathrm{Na}$ Coxilha Rica ainda encontram-se preservados boa parte desses caminhos erguidos em taipa, bem como muitas fazendas centenárias, que acabaram por criar um conjunto de remanescentes histórico, cultural, arquitetônico e paisagístico, inexistentes em outras regiões do Brasil por onde o Tropeirismo se estendeu. Em muitos trechos desses caminhos e fazendas, o estado de conservação ainda é grande e merecem ser preservados.

A Coxilha Rica possui alguns dos principais rios que constituem nascentes do Rio Uruguai, formada por extensas áreas de campos e vales encaixados que drenam um grande volume de águas e proporcionam um rico potencial hidreléctrico. Na época de desenvolvimento deste trabalho existiam diversos projetos de aproveitamentos energéticos aprovados pela Agência Nacional de Energia Elétrica (ANEEL) que estavam em fase de licenciamento ambiental.

O IPHAN, preocupado com a preservação, levando em consideração o número expressivo de Pequenas Centrais Hidreléctricas (PCH) em estudo, solicitou que as empresas envolvidas nos empreendimentos desenvolvessem um método em conjunto para minimizar os impactes futuros a serem causados na área. Tal preocupação foi relevante, não somente pelos danos ambientais que poderiam ser causados, mas também devido ao impacte visual decorrente da inserção de sistemas de transmissão no ambiente cênico. 
Portanto, em agosto de 2009, o IPHAN, a Eletrobras Eletrosul e a Gomes Lourenço Empreendimentos e Participações (GLEP) assinaram o "Termo de Referência para Pesquisa Arqueológica", cuja finalidade foi subsidiar o processo de licenciamento ambiental dos seus empreendimentos energéticos na Coxilha Rica (ABATI ET AL, 2010), cujo objectivo era minimizar impactes, sobretudo visual, no ambiente cênico da região da Coxilha Rica e proporcionar ao IPHAN, subsídio para a análise e gestão do território, bem como para o controle das solicitações de intervenção no espaço em questão, considerando a importância dos investimentos de infraestrutura para a sociedade brasileira e a preocupação com a preservação do patrimônio histórico, cultural e paisagístico da região.

Devido a essa necessidade, a pesquisa tornou-se relevante cientificamente, principalmente por desenvolver metodologia de suporte, ferramenta e produtos cartográficos para tomada de decisão nas análises de intervenção na paisagem.

Diante da necessidade de preservação desse importante patrimônio e, em atendimento às condicionantes impostas à época, devido ao licenciamento ambiental das PCH que iriam ser implantadas na região da Coxilha Rica, iniciaram-se as pesquisas históricas e outros estudos, que visaram à minimização de possíveis impactes visuais no sistema de transmissão de energia (para escoar a energia gerada pelas $\mathrm{PCH}$ ) sobre a paisagem, causados pelas estruturas e cabos que transportariam eletricidade para os centros consumidores.

Neste ínterim foi desenvolvido um projeto cujos resultados foram apresentados por Celestino et al (2010) e Abati et al (2010), que consistiu em desenvolver e aplicar na área de influência direta das $\mathrm{PCH}$ da Coxilha Rica, uma metodologia reproduzível para tomada de decisão nas análises de intervenção da paisagem, onde foram identificados, caracterizados e mapeados elementos da região, bem como estruturado um banco de dados histórico, fotográfico e cartográfico.

Foram também geradas poligonais de visibilidade, donde foram definidas alternativas para projetos de sistemas de transmissão de energia eléctrica, utilizando torres de transmissão com altura de $24 \mathrm{~m}$ (estrutura metálica em forma de torre que sustenta uma série de cabos através dos quais é transportada a energia eléctrica). Ver exemplo de torre de transmissão na figura 03. 
Para apresentação final do projeto foram gerados mapas temáticos em diferentes escalas. 0 método produzido visou à eliminação e/ou minimização do impacte visual sobre o ambiente cênico da região da Coxilha Rica.

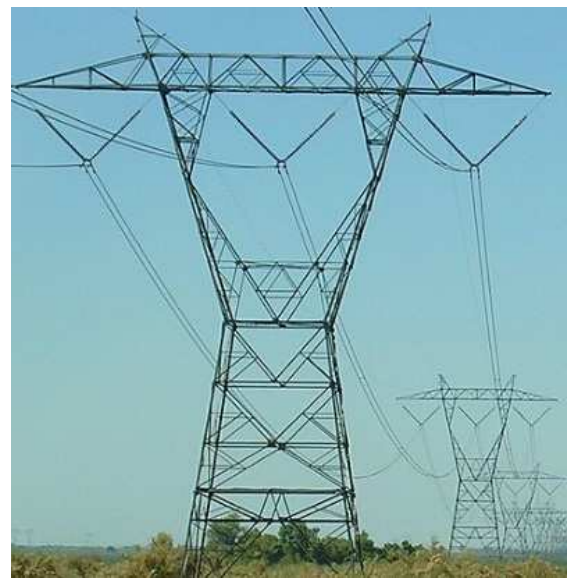

Figura 03 - Exemplo de Torres de Transmissão Fonte: Wikipedia (2016)

Já no início do projeto foi identificada a necessidade de se delimitar a área das poligonais que seriam geradas. Para tanto foram desenvolvidos estudos específicos para estimar o alcance visual humano e delimitar a área de abrangência dos subsequentes estudos e aplicações. Os resultados provenientes deste estudo específico estão sendo apresentados neste trabalho.

\section{Objectivos}

Este artigo tem por objectivo determinar um raio de abrangência virtual a ser considerado na geração de poligonais de visibilidade que leve em consideração a acuidade visual humana, visando à eliminação/minimização de impacte(s) visuais na paisagem ocorridos pela inserção de torres de transmissão. Para tanto os seguintes objectivos específicos foram definidos:

- Determinar o alcance visual linear e logarítmico humano e utilizar como referência a Tabela de Snellen; 
- Calcular, através de relações trigonométricas, o alcance visual humano na paisagem da Coxilha Rica através dos limites físicos da acuidade visual humana, da curvatura terrestre e da refração atmosférica, utilizar como objeto de estudo uma torre de transmissão de $24 \mathrm{~m}$ a ser percebida por um observador humano na paisagem da Coxilha Rica.

\section{Conceituação Teórica}

A rever a bibliografia brasileira especializada não se verificou, à época, nenhum estudo ou experiência sobre a definição da amplitude do alcance visual humano ou as interferências atmosféricas levadas em consideração para apoiar o desenvolvimento de poligonais de visibilidade no Brasil.

Desta forma para uma definição criteriosa, com base científica, foi necessário rever os estudos de teorias sobre cognição e perceção espacial e ambiental, acuidade visual humana, paisagem e impacte visual em bibliografia internacional.

\subsection{Cognição e Perceção Espacial, Impacte Visual na Paisagem}

A maioria dos trabalhos que envolvem os termos perceção visual, cognição e impacte visual são subjetivos e muito variados. Existem poucas propostas de identificação de pontos significativos, desde observação ou entrevistas até decomposição da paisagem em elementos ordenadores dos usos e arranjos espaciais, sobretudo sobre como mapear a mancha de visibilidade alcançada a partir de pontos escolhidos como principais (MOURA, 2003).

Conceptualmente a cognição espacial é um processo complexo que resulta da interação entre o sistema sensório-motor e as estruturas neurológicas responsáveis pelo sistema cognitivo do indivíduo (LIMA, 2004) e as bases da perceção espacial são fisiológicas e anatômicas, ocorrendo também mediante os órgãos sensoriais. No caso da perceção ambiental o órgão mais usual é o da visão, órgão por onde os homens se expressam e se 
comunicam. O mundo moderno é dominado pelo campo visual, cores, formas e imagens (OLIVEIRA E MACHADO, 2001). Já a atenção como um processo mental, quando o foco é voltado para o ambiente externo, pode ser denominada de perceção seletiva; e quando é voltada ao ambiente interno, pode ser denominada de cognição seletiva (GAZZANIGA ET AL, 1998).

A perceção é obtida através da refração, que na visão humana ocorre quando o feixe de luz, vindo do ambiente externo, atravessa todo o globo ocular para formar a visão na retina, situada no fundo do olho. A incidência da luz na retina é que permite a formação da imagem retiniana em duas dimensões. Essa visão corrobora com a descrição de Stolfi (2008) "a perceção visual é um processo de reconstrução da realidade exterior, realizado pelo córtex cerebral, a partir de informações fragmentadas captadas pelos olhos".

Já a avaliação de impacte visual é bem reconhecida na literatura de paisagem (SMARDON ET AL, 1983), mas a delimitação desse limiar é problemático. Os últimos estudos de impacte visual preocuparam-se com a avaliação da qualidade visual ou com os níveis de impactes visuais ocorridos por modificações na paisagem. A avaliação visual depende, para além do caráter visual da cena, dos critérios de julgamento interno dos espectadores. Esses critérios podem variar significativamente de indivíduo para indivíduo, gerando uma grande diversidade de critérios.

Mensurações precisas, objectivas e confiáveis estão se tornando cada vez mais importantes nas avaliações de impacte visual. A pesquisa quantitativa em perceção visual ambiental é um passo vital no âmbito da avaliação de impacte visual, incluindo a modelação qualitativa visual e os impactes da utilização de Sistemas de Informação Geográfica (SIG) baseado em variáveis (BISHOP e HULSE, 1994).

Esses modelos dependem da estimativa de atributos visuais que são bons previsores de valores visuais, pois restringem a área sobre a qual a modelação será aplicada, reduzindo os esforços e o tempo de levantamento e processamento de dados. A escassez de estudos sobre os limiares existentes reflete a enorme dificuldade e complexidade associadas à mensuração e monitoramento de atributos das componentes da paisagem, fazendo com que algumas dúvidas em relação a eles persistam, até mesmo em relação a sua possibilidade (CARLSON, 1977). Os principais atributos da paisagem podem incluir 
propriedades físicas visuais tais como o tamanho, o contraste, a cor, a forma, a textura, o padrão e a complexidade, etc. Potencialmente estas propriedades podem ser medidas e os seus limiares visuais podem ser definidos através deles.

Moura (2003) propôs uma metodologia para geração de mapas que retratassem o alcance de eixos visuais a partir de pontos notáveis da paisagem na cidade de Ouro Preto/MG (Brasil) e a partir da escolha de uma rede de pontos principais na observação da paisagem urbana construiu manchas de áreas de influência visual. O método foi utilizado com a finalidade de verificar as intervenções em atividade de mineração e construções em áreas de valor histórico. A proposta trouxe o ganho conceptual, pois superou as análises que representam o espaço de modo somente bidimensional, com olhar zenital da projeção ortogonal no território para uma representação análoga a do olhar humanizado, através de mapeamento azimutal, a considerar a escala humana na leitura da realidade espacial urbana. Delimitou como área de estudo um rectângulo de 8,0 km por 5,0 km.

A autora chegou à conclusão de que uma área classificada com alto grau de visibilidade é vista de grande parte dos principais pontos do conjunto e qualquer intervenção não adequada traz sérias consequências na paisagem.

Neste contexto, no trabalho desenvolvido por Abati et al (2010), foram utilizadas duas abordagens científicas, uma qualitativa e uma quantitativa, para a determinação de poligonais de visibilidade para verifiicar o impacte visual causado quando da inserção de elementos na paisagem. A abordagem qualitativa se valeu de conceitos referentes a paisagem, cognição e perceção espacial e ambiental como forma de incluir o contexto aqueológico, paisagístico e ambiental à pesquisa. A abordagem quantitativa, por sua vez, tratou das adaptações das formulações físicas e geométricas existentes no mundo lógico para retratar e mapear as características físicas inerentes entre a perceção humana e a paisagem, diminuindo assim, a abrangência espacial do trabalho.

\subsection{Efeitos Atmosféricos e a Curvatura Terrestre}

Alguns fatores inerentes à natureza podem interferir na correta captação e perceção das imagens pelo ser humano. Quanto maior a quantidade de luz e menor a distância de 
observação, melhor será a imagem formada, menor será a influência dos efeitos atmosféricos, e suas consequentes mudanças na velocidade da radiação, no comprimento de onda, na intensidade e na distribuição espectral. Um dos fenômenos que mais interfere a captação e perceção de imagens é a refração atmosférica (MIGUENS, 2000).

O índice de refração (n) é uma razão entre a velocidade da luz no vácuo (c) e a velocidade da luz numa substância como a atmosfera ou a água $\left(c_{n}\right)$. A velocidade da luz numa substância nunca pode atingir a velocidade da luz no vácuo. Portanto, o índice de refração sempre deve ser maior que 1. A refração pode ser descrita pela Lei de Snell - Descartes.

Outro efeito ocasionado pela atmosfera é o espalhamento da radiação pelas partículas atmosféricas. Existem três tipos de espalhamento, de acordo com Meneses e Almeida (2012): Rayleigh ou espalhamento molecular, Mie ou espalhamento não molecular e espalhamento não seletivo.

De acordo com Silva (2010), a curvatura terrestre e as diferentes densidades nas camadas da atmosfera afetam as observações, principalmente quando as visadas são extensas. Podese afirmar que para cada ponto na superfície terrestre existem três horizontes distintos: $\underline{\text { Aparente: }}$ horizonte tangente à superfície da terra (plano horizontal topográfico); Óptico: horizonte que enxergamos (efeito da refração atmosférica); Verdadeiro: corresponde a mesma altitude do ponto inicial da visada. Para corrigir os efeitos da curvatura e refração atmosférica calculam-se os valores conforme a equação a seguir:

$$
D H^{2}+R^{2}=(R+C)^{2}
$$

Onde:

DH = distância horizontal

$\mathrm{R}=$ Raio médio elipsoidal da Terra (6370000 m)

$C=$ Curvatura Terrestre

De acordo com Silva (2010), ao dividir $\mathrm{DH}^{2}$ por $(2 * 6370000 \mathrm{~m})$ ou dividir por $(2 * 6370000$ $m+C)$, o resultado será muito semelhante. Por isso pode-se descartar " $C$ " do lado direito da igualdade, resultando em:

$$
C=\left(D H^{2}\right) / 2 R
$$


De acordo com o autor, o deslocamento devido à variação do índice de refração equivale a $13 \%$ do valor de " $C$ ". Denota-se por " $r$ " o efeito da refração. ( $C-r$ ) é o valor que deve ser corrigido, ou seja, do Horizonte Ótico (Ho) ao Horizonte Verdadeiro (Hv).

$$
r=0,13 C
$$

Entra-se com o valor de "DH" em metros e obtém-se o resultado em metros.

De acordo com os cálculos de Espartel (1965), a máxima precisão relativa alcançada nas medidas topográficas é um milionésimo, resultando que dentro de um raio de $10 \mathrm{~km}$ é possível considerar plana a superfície terrestre para os levantamentos planimétricos. 0 mesmo não ocorre para a altimetria, pois existe o erro de esfericidade, cujo valor é obtido através da fórmula:

$$
\mathrm{DH}_{1}=\mathrm{DH}^{2} / 2 \mathrm{R}
$$

Onde:

$\mathrm{DH}_{1}=$ diferença de altura/cota

Devido à refração este erro é realmente menor, pois o plano traçado não é uma linha reta e sim uma curva com a curvatura voltada para o centro da Terra. Assim o erro fica diminuído quando considerado o abaixamento de Gauss (G) de 0,1360 h. Assim o erro de esfericidade e refração fica reduzido a:

$$
\mathrm{G}_{\mathrm{i}}=0,87 * \mathrm{DH}^{2} / 2 \mathrm{R}
$$

\subsection{Tabela de Snellen e a Acuidade Visual Humana}

Resumidamente a perceção visual pode ser descrita através dos fenômenos lógicos, desde que alguns critérios sejam levados em consideração, como por exemplo, a escala, a localização, a altura de observação, entre outros. Ao ponderar a escala, convém lembrar que o homem é a medida, levando-se em conta a posição ereta, o movimento e a perspectiva.

De acordo com Meneses e Almeida (2012) o estímulo de perceção visual do olho humano é não linear. Devido a isso foi estabelecida a Lei de Weber-Fechner, que se baseia em um 
modelo logarítmico da perceção subjetiva de estímulos, para os quais somente a diferença de brilho é perceptível (STOLFI, 2008). Ver figura 04.

A Acuidade Visual (AV) é a capacidade de discriminar os detalhes dos objetos no campo de visão, determinada pela dimensão mínima de alguns aspetos espaciais dos estímulos visuais, referindo-se ao limite espacial da discriminação visual. A AV depende das propriedades ópticas do olho (de gerar uma imagem precisamente focalizada), da capacidade da retina em detectar e processar os estímulos visuais, gerando sinais neurais, e da interpretação desses sinais pelas vias visuais superiores (CARMONA ET AL, 2006).

Baseado nisso foi verificado que a AV é proporcional ao logaritmo da intensidade do estímulo, que deve crescer exponencialmente para que a vista humana consiga diferenciá-la conforme aumenta a distância em relação ao objeto observado.

Em termos quantitativos e mensuráveis a AV se refere à capacidade do sujeito em detetar, separar ou discriminar um objeto no espaço. Estas capacidades correspondem, respectivamente, ao menor objeto detetável (acuidade de deteção), à menor distância entre dois objetos que permita detetá-los como dois (acuidade de separação ou de resolução) e ao menor objeto discriminável ou reconhecido (acuidade de discriminação ou de reconhecimento) (CARMONA ET AL, 2006).

De acordo com Schiff (1980), uma pessoa com AV normal pode distinguir alto contraste de linhas, barras ou padrões quadrados, com separação de mais ou menos 1 minuto de arco. Dados semelhantes também foram relatados por Selkurt (1961), Riggs (1971) e McBurney e Collings (1984).

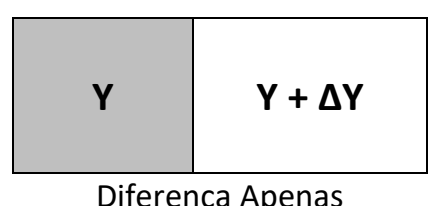

Diferença Apenas Perceptível de Brilho

$$
\rightarrow \frac{\Delta Y}{Y} \approx 0.02 \text { (Lei de Weber) }
$$

\section{Figura 04 - Lei de Weber}

Fonte: Adaptado de Stolfi (2008)

De acordo com a Biblioteca Virtual em Saúde (2010), em termos físicos a AV normal (humana) é expressa como 20/20, que indica que uma pessoa pode enxergar a 20 pés 
(aproximadamente $6,096 \mathrm{~m}$ ) o que normalmente deve ser visto a esta distância. A AV é influenciada por brilho, cor e contraste e pode ser medida através de escalas optótipos.

A tabela, o optótipo ou a escala optométrica de Snellen é um diagrama utilizado para avaliar a acuidade visual de uma pessoa. Possui subdivisões da escala e respeita as limitações da AV humana de um minuto de grau. No quadro de Snellen as menores letras legíveis a uma distância de 6,098 m (20 pés x 30,48 cm) por uma pessoa com a visão perfeita, são da linha 20. A AV por sua vez é representada como uma fração, sendo o numerador (topo da fração) a distância em que o observador está e o denominador (parte de baixo de fração), a distância máxima legível do quadro.

O ser humano enxerga objetos em um campo visual pré-definido, que corresponde à área total ou espaço visível na visão periférica com o olho direcionado para frente. A extensão média é de aproximadamente 65 acima, 75 abaixo, 60ำ para dentro e 95으 para fora. Já o campo visual humano binocular é de aproximadamente 124․ Campos visuais podem ser medidos pela perimetria e podem ser análogos aos eixos visuais utilizados em mapeamento. Ao estudar a ligação entre a variação nas características específicas de estímulo ambiental e a experiência subjetiva, um limiar visual é no final uma capacidade do sistema sensorial e pode ser considerado como a quantidade mínima que pode ser detetada pelo olho humano. O limite permeia entre o detetar e o não detetar e raramente possui um valor absoluto (SHANG e BISHOP, 2000).

De acordo com Shang e Bishop (2000) as pesquisas de laboratório relacionadas ao impacte visual normalmente produzem curvas em forma de 'S", como mostrado na figura 05 (função de limite empírico), indicando que à medida que o nível de energia aumenta também há um aumento na probabilidade do estímulo que será detetado pelo olho humano. $\mathrm{O}$ valor limite é geralmente e arbitrariamente, calculado para corresponder à determinada magnitude do estímulo, provocando uma resposta de detecão na metade das vezes, 50 por cento do tempo. Porém o resultado obtido é bastante difícil de utilizar diretamente na modelação de impacte visual e os autores reconhecem que a aplicação é limitada quando são introduzidos elementos na paisagem. 


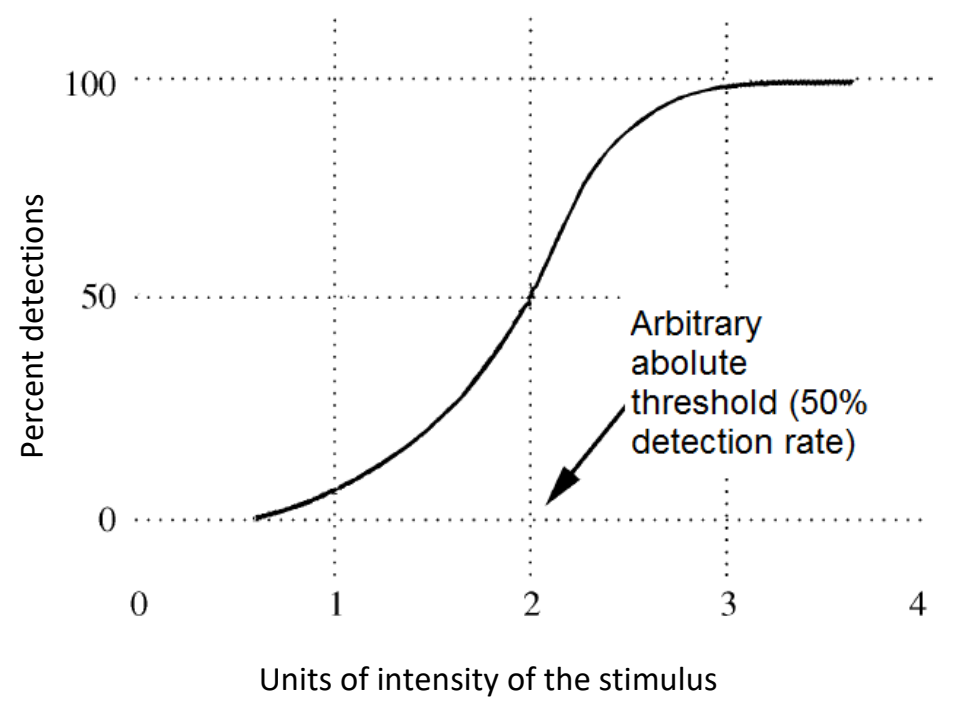

Figura 05 - Função de limite empírico

Fonte: Adaptado de Shang e Bishop (2000)

Para resolver esse problema Shang e Bishop (2000) desenvolveram técnicas de imageamentos computacionais para simular uma paisagem hipotética e realizar modificações altamente realísticas. Foram utilizados conceitos psicofísicos para determinar o limiar visual (acuidade de deteção e de reconhecimento). Os atributos visuais, tais como tamanho, contraste, forma e ajuste da paisagem foram utilizados como variáveis experimentais. As equações de limiar obtidas por eles podem ser utilizadas para estabelecer padrões visuais e ordenanças, bem como ser utilizadas em sistemas de modelação de computador para o planeamento e gestão da paisagem. Introduziram, então, o conceito de meio limiar de impacte visual, do original em inglês Medium Visual Impact Threshold (MVIT).

O MVIT pode ser definido como o estado físico de um objeto no qual 50 por cento das avaliações de impacte dos telespetadores, com base em cenas originais e alteradas, quando mostradas lado a lado, excedem a posição intermediária entre baixo e alto nível de impacte visual. No conceito do MVIT um objeto tem apenas de ser detetável para potencialmente provocar um impacte visual. Foram utilizadas imagens com inserção das torres de transmissão de 9 m e 30 m, mas com uma distância de visualização simulada de somente 100 m. Não foram realizados testes com distâncias maiores. 


\section{Método}

Para executar o trabalho dentro de um limite espacial nas áreas onde seriam inseridos elementos que supostamente provocariam impacte visual, em primeiro lugar, foram utilizadas formulações que envolveram a delimitação física da superfície terrestre e a limitação da acuidade visual humana.

Os assuntos abordados e os resultados obtidos nessa etapa focaram na determinação de uma distância limite ideal a ser alcançada pela visão humana em condições normais. Para tanto foi calculado para distâncias pré-determinadas, o abaixamento segundo Gauss, para levar em consideração a curvatura terrestre e a refração atmosférica.

A AV foi utilizada como ângulo da tangente formada pela distância vertical da AV humana projetada no anteparo e pela distância ao anteparo, para calcular o valor da acuidade visual de forma linear, relativa ao limite estabelecido de um minuto de grau (1'), de acordo com a descrição do item 3.3.

Na Tabela de Snellen a distância vertical compatível com o intervalo angular de 5 minutos, para a distância horizontal ao anteparo de 6,096 m, é de 0,0887 m, que resulta no ângulo de 1 minuto na distância linear de 0,01774 m.

Para continuidade do trabalho e estabelecimento de relações, definiu-se que o menor objecto a ser visualizado por um observador (ser humano com visão normal), independente da distância de observação, quando utiliza um anteparo de 6,096 m, não deveria ser menor do que $0,01774 \mathrm{~m}$, pois de acordo com as referências, um objeto menor que este valor é imperceptível à visão humana.

Foi definida como objecto de estudo uma torre de transmissão de energia, cuja definição foi fundamental para continuidade dos cálculos subsequentes da máxima distância percebida a olho nu por um observador na área de estudo em questão. Para realizar esse cálculo, foram utilizadas escalas logarítmicas e adaptações da tabela de Snellen. O procedimento de cálculo realizado está descrito a seguir:

- Definição da altura da torre de transmissão de energia eléctrica $\left(H_{T}\right)$ a ser locada pelos empreendedores na região em 24 m; 
- Definição da distância horizontal $\left(D_{A}\right)$ para um anteparo de acordo com a definição optométrica de Snellen em 6,098 m;

- Determinação do raio médio elipsoidal da Terra em 6370000 m.

As distâncias horizontais pré-determinadas foram reduzidas através do abaixamento de Gauss (Equação 05):

$$
\mathrm{G}_{\mathrm{i}}=0,87 *\left(\mathrm{DH}_{\mathrm{i}}\right)^{2} / 2 \mathrm{R}
$$

A altura da torre de $24 \mathrm{~m}$ também foi reduzida com base nas novas distâncias horizontais reduzidas, através da equação 06, a seguir:

$$
H_{i}=H_{T}-G_{i}
$$

Onde:

$\mathrm{G}_{\mathrm{i}}=$ Abaixamento de Gauss

$\mathrm{DH}_{\mathrm{i}}=$ distâncias horizontais entre observador e torre de transmissão

$\mathrm{H}_{\mathrm{i}}=$ altura da torre de transmissão reduzida

$\mathrm{H}_{\mathrm{T}}=$ altura da torre de transmissão de $24 \mathrm{~m}$

$\mathrm{R}=$ raio médio elipsoidal da Terra de $6370000 \mathrm{~m}$

Após a determinação da nova altura percebida pela visão da torre, foi calculada a respectiva altura da torre projetada no anteparo, como uma simulação. A determinação de um anteparo foi necessária para estabelecer as relações trigonométricas entre o observador, a AV e a projeção da visão da torre no anteparo. Neste cálculo a determinação se deu de maneira linear.

Através de relações trigonométricas foi determinada cada altura da torre reduzida e projetada no anteparo, utilizando como base a distância ao anteparo de 6,096 m, bem como as distancias horizontais reduzidas. A relação resultou na equação 07 a seguir:

$$
\left(D_{A} * H_{i}\right) / D H_{i}=h_{i}
$$

Onde:

$D_{A}=$ distância horizontal do anteparo de 6,098 m 
$h_{i}=$ distância vertical da AV projetada no anteparo

Em condições reais, o estímulo cresce de forma exponencial para que possa ser percebido pelo olho humano conforme a distância aumenta. Para essa situação foram calculadas as mesmas relações trigonométricas, só que com os valores da altura reduzida da torre na escala logarítmica, conforme a equação 08 a seguir:

$$
\left(D_{A} *\left(H_{i}-\left(\ln H_{i}\right)\right) /\left(D h_{i}\right)=h_{i}(\ln )\right.
$$

Como forma de validar o método, algumas poligonais de visibilidade foram geradas através de pontos de observação, pela ferramenta "Viewshed" do ArcGIS. Para tanto foram utilizadas bases cartográficas oficiais do Estado de Santa Catarina na escala 1:50.000, Modelo Digital de Elevação (MDE) do Advanced Spaceborne Thermal Emission and Reflection Radiometer (ASTER) com resolução planimétrica de $30 \mathrm{~m}$ e altimétrica de $20 \mathrm{~m}$ e imagens orbitais do Satélite SPOT do ano de 2001, com resolução espacial de 10 m. Foram realizadas simulações, onde o software virtualmente realizou um caminho sobre o corredor de pedras, o que resultou em diferentes áreas visualizadas para cada ponto percorrido e foram escolhidos pontos de referência, para realizar a validação do método. Dessa forma a poligonal simulou a distância percorrida pelo olhar humano no horizonte por eixos visuais a considerar as elevações existentes ao redor do ponto de observação da paisagem.

O resultado por ponto foi verificado in loco pela equipa do projeto, através de fotografias (retiradas por semiquadrantes) e levantamentos a 360 (45 para cada semiquadrante, iniciando no setor 01 situado entre os graus 0 으 e 45으) por estação total colocadas no ponto de referência e medição por prismas nos limites dos eixos visuais mapeados. Tal procedimento permitiu verificar se a visão no ambiente virtual era correspondente à da visão real do observador. A qualidade obtida na avaliação, considerada boa, permitiu a utilização do método para a geração dos demais produtos. Todo o procedimento foi analisado e verificado in loco pelo IPHAN.

Não é objectivo deste trabalho apresentar a geração das poligonais de visibilidade na região da Coxilha Rica, nem a avaliação de qualidade do método utilizado. Maiores detalhes sobre o método, a avaliação e o material utilizado podem ser consultados em Abati et al (2010). 


\section{Resultados}

O primeiro resultado foi a definição de um limite para os cálculos posteriores com base na acuidade visual humana. De acordo com as referências apresentadas esse pode ser considerado como valor limite para que um ser humano, com sua visão em condições normais, consiga diferenciar elementos em uma projeção num anteparo de 6,096 m. O valor da acuidade de forma linear resultou em $0,01774 \mathrm{~m}$, considerado compatível com a acuidade visual humana de 1 minuto de grau. Objectos menores que esse valor são imperceptíveis, portanto, para a visão humana.

Após foram calculados o abaixamento de Gauss, que levou em consideração, tanto a curvatura terrestre quanto a refração atmosférica relacionada com a distância percorrida na paisagem de forma linear. Ver os valores calculados no Anexo A “Determinação da Acuidade Linear", na coluna $G_{i}(m)$.

Os valores calculados do Abaixamento de Gauss foram subtraídos do valor definido para a torre de transmissão de $24 \mathrm{~m}$, pois conforme a distância aumenta, ocorre um abaixamento da feição no horizonte em relação ao observador. Os valores reduzidos para a torre estão sendo apresentados no Anexo $A$, na coluna $\mathbf{H}_{\mathrm{i}}(\mathrm{m})$.

Através de relações trigonométricas foram calculados os valores reduzidos da torre de transmissão, levando em consideração a distância horizontal linear e a distância do anteparo de 6,096 m. Os valores estão sendo apresentados no Anexo $A$, na coluna $\mathbf{h}_{\mathbf{i}}(\mathbf{m})$.

Através de relações trigonométricas foram calculados os valores logarítmicos reduzidos da torre de transmissão, levando em consideração a distância horizontal e a distância do anteparo de 6,096 m. Esses cálculos levam em consideração o estímulo visual exponencial para perceção visual conforme a distância entre observador e objecto aumenta. Os valores estão sendo apresentados no Anexo A "Determinação da Acuidade Linear", na coluna $\mathbf{h}_{\mathbf{i}(\mathbf{I n})}$ (m).

Para realizar todos os cálculos foram determinadas 100 distâncias horizontais (N) entre os $100 \mathrm{~m}$ e os $10000 \mathrm{~m}$. No Anexo citado, especificamente a partir da linha 71, os resultados gerados mostram que, a partir de uma distância de $7100 \mathrm{~m}$, a considerar somente os cálculos lineares, a projeção da visão da torre no anteparo é menor que o valor 
determinado de 0,01774 m perceptível pela AV humana, o que significa que, a partir dessa distância, a visão perde nitidez e a torre de 24 m passa a não ser mais percebida pelo observador.

Se levarmos em consideração que o estímulo deve ser exponencial para o objecto poder ser perceptível pelo observador humano conforme se distancia do mesmo, podemos levar em consideração os valores gerados a partir da linha 63 , onde os resultados gerados mostram que, a partir da distância de 6300 m, nos cálculos logarítmicos, a projeção da visão da torre no anteparo é menor que o valor determinado de 0,01774 m perceptível pela AV humana, o que significa que, a partir desta distância, a visão perde nitidez e a torre de 24 m passa a não ser mais percebida pelo observador.

Está sendo apresentado de forma adicional uma poligonal de visibilidade (figura 06) gerada através de um ponto em determinada fazenda na área de estudo, que levou em consideração o valor limite de 8000 m (definidos por questões de segurança e confiabilidade como limite) como raio para a geração dos eixos visuais.

Na figura 06 pode ser percebida a setorização realizada por semiquadrantes, a simular os eixos visuais humanos em até $8000 \mathrm{~m}$, bem como a área de visibilidade mapeada na cor vermelha e seu respectivo alcance virtual. Devido ao relevo ondulado, característico da área de estudo, a maioria da região mapeada a partir do horizonte do observador não pôde ser visualizada, mesmo em distâncias menores que 8000 m.

A partir do mesmo ponto de referência (ponto de vista do observador) foram realizadas validações por fotografias pela equipa de campo do projeto. Tais fotografias foram retiradas a partir de cada ponto de vista por semiquadrantes. Ver figuras de 07 a 14, onde pode ser percebido que nos setores 03 e 05 (figuras 09 e 11) o alcance visual é maior devido à maior abertura do horizonte, porém não foi possível perceber a localização da equipa em campo a olho nu na distância mapeada de maior distância. Foi verificado empiricamente em campo que a visão humana perde completamente a nitidez em longas distâncias, principalmente a partir dos $6000 \mathrm{~m}$. 


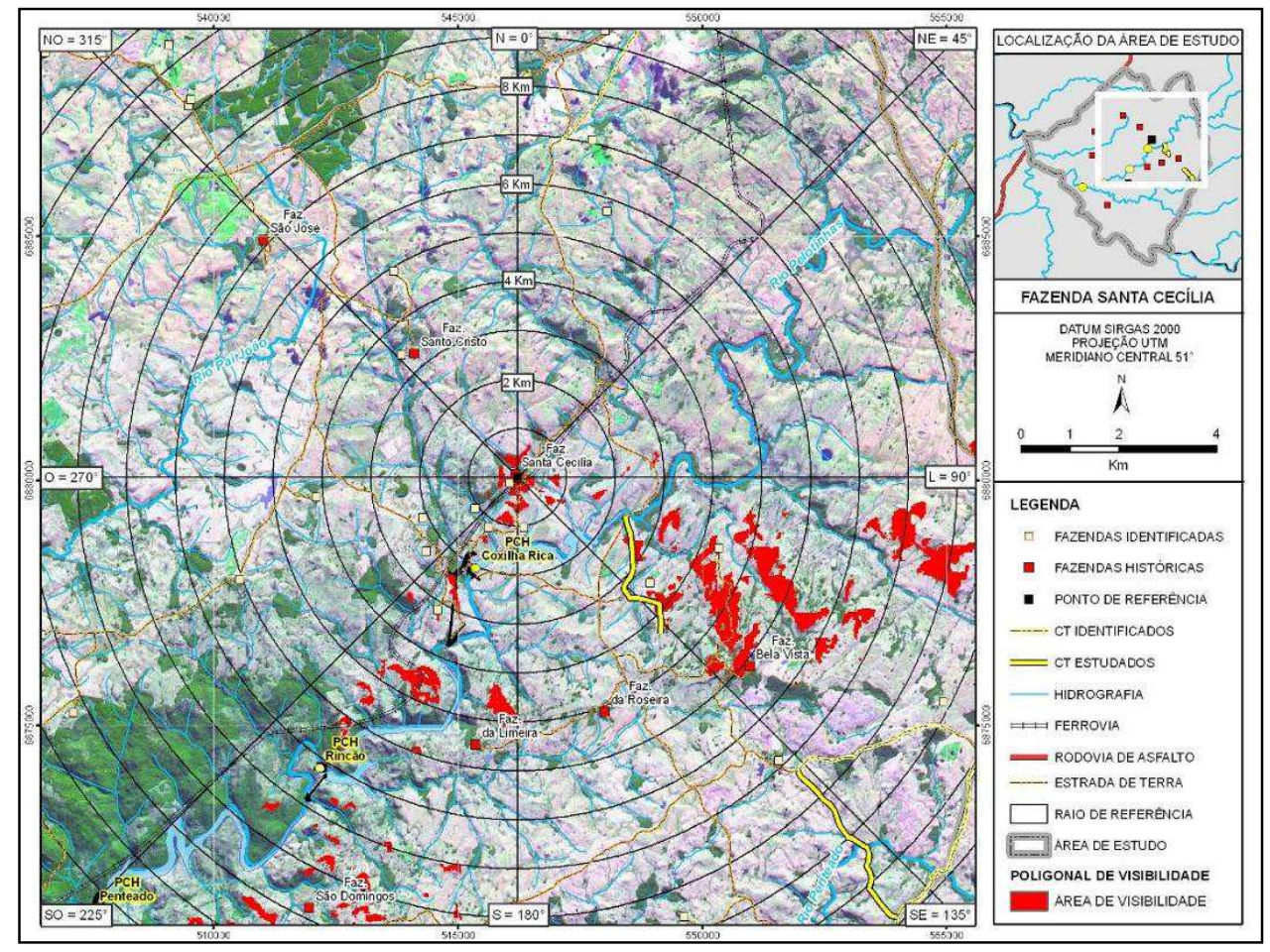

Figura 06 - Poligonal de visibilidade do ponto de referência

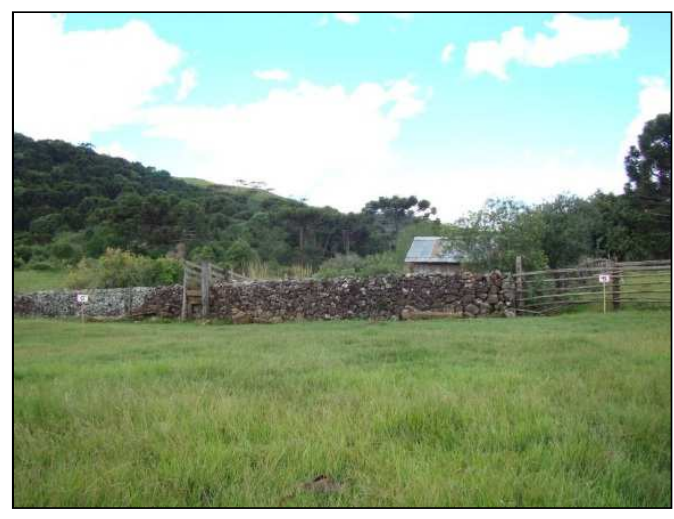

Figura 07 - Setor 1 ( $0^{\circ}$ a $45^{\circ}$ )

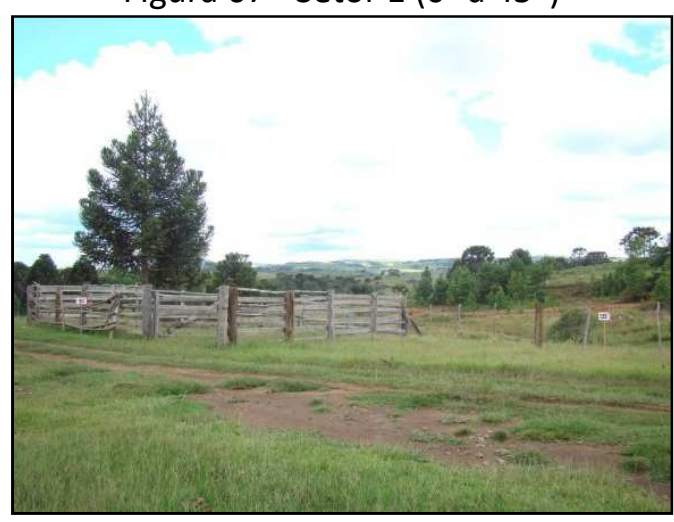

Figura 09 - Setor $3\left(90^{\circ}\right.$ a $\left.135^{\circ}\right)$

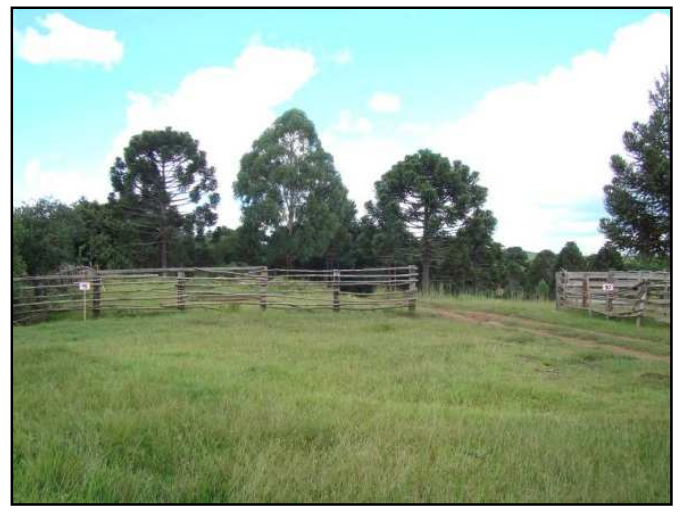

Figura 08 - Setor 2 (45 a 90ㅇ)

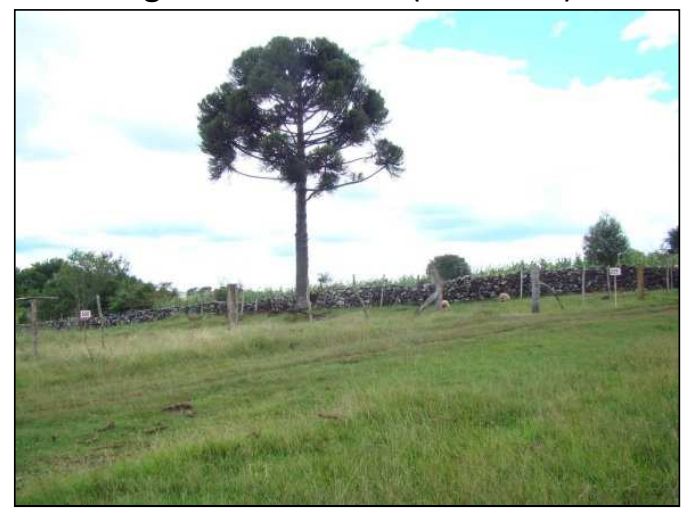

Figura 10 - Setor 4 (135ㅇ a $\left.180^{\circ}\right)$ 


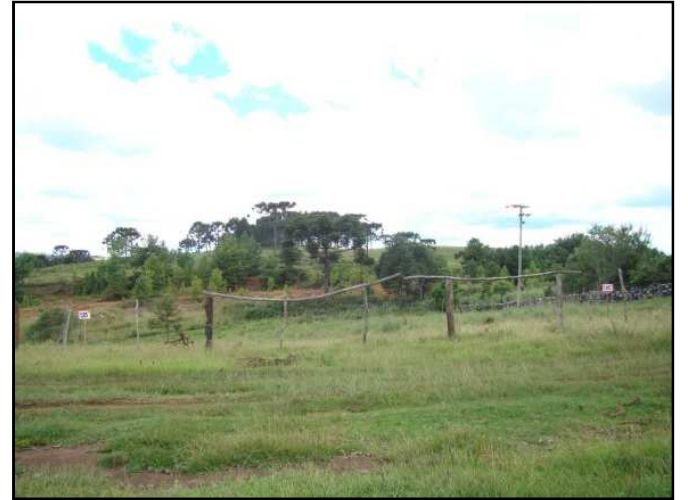

Figura 11 - Setor $5\left(180^{\circ}\right.$ a $225^{\circ}$ )

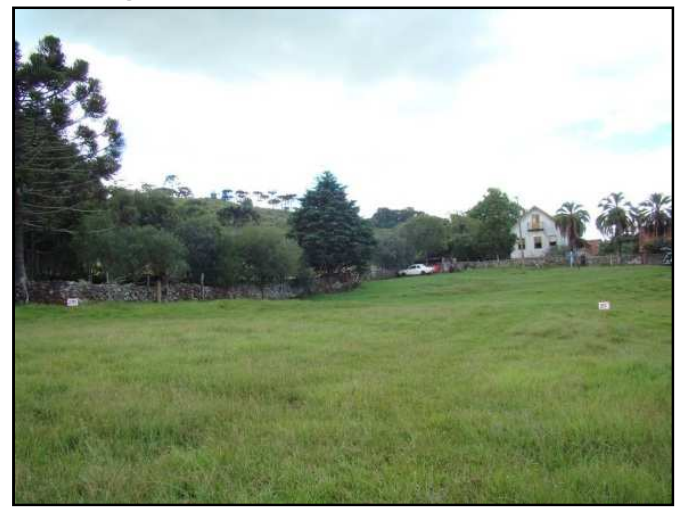

Figura 13 - Setor $7\left(270^{\circ}\right.$ a $\left.315 \circ\right)$

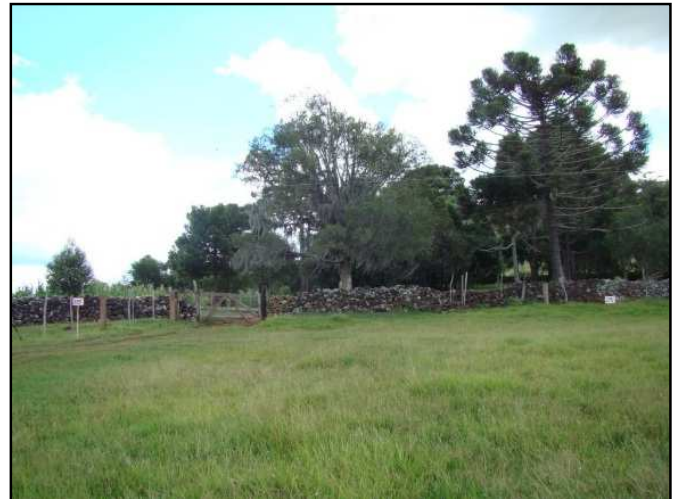

Figura $12-$ Setor $6\left(225^{\circ}\right.$ a 270 은

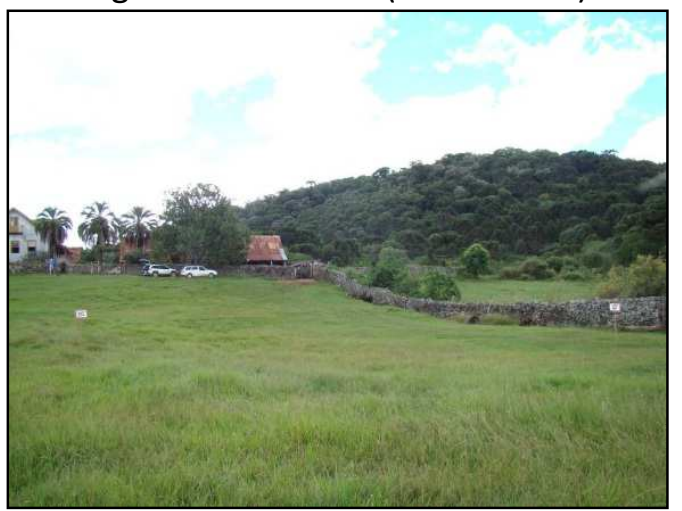

Figura 14 - Setor $8\left(315^{\circ}\right.$ a 0 으)

\section{Conclusões}

Chega-se a conclusão que todos os objectivos foram atingidos, pois foi determinada a acuidade visual humana de forma linear em 0,01774 m, a estabelecer um padrão quando relacionado um anteparo de 6,096 $\mathrm{m}$ (Tabela de Snellen).

Como objecto de estudo foi utilizada uma torre de transmissão de energia de $24 \mathrm{~m}$ de altura e a partir da determinação da acuidade linear e logarítmica foram estabelecidas relações trigonométricas que levaram em consideração limites físicos terrestres e humanos e consequentemente limitaram a geração de poligonais de visibilidade, por raios (eixos visuais a partir de um observador humano com condições visuais normais) de, respectivamente, 7100 m para os cálculos realizados de forma linear e 6300 m para a forma logarítmica de cálculo, para um determinado observador deixar de observar a torre de transmissão no horizonte. 
Foi estabelecido, por segurança, em 8000 m, o limite para realizar as avaliações do método, in loco.

Analiticamente o método utilizado consistiu em gerar limites físicos para mapear as poligonais (áreas) de visibilidade alcançada por um indivíduo posicionado a partir das fazendas históricas e/ou caminhos de tropas com a finalidade de eliminar ou minimizar o impacte visual causado pelas futuras torres de transmissão sobre o ambiente cênico da paisagem da Coxilha Rica.

As poligonais de visibilidade geradas após a delimitação de área proposta neste trabalho permitiram que os empreendedores do setor energético projetassem seus sistemas de transmissão de energia de forma a diminuir os impacte(s) ambiental, paisagístico e visual sobre os aspetos históricos e arqueológicos existentes, o que garantiu um melhor planeamento e gestão do território da Coxilha Rica. Foi possível apresentar aos órgãos licenciadores diversas alternativas para o sistema e tomar a decisão de forma a apresentar nenhum ou o menor impacte possível.

O estabelecimento de limites territoriais para produção de poligonais de visibilidade foi considerado uma etapa importante e fundamental durante todo o projeto, pois forneceu subsídios aos executores, bem como aos órgãos licenciadores para definir e reduzir geograficamente o território onde seriam realizadas as intervenções futuras, bem como a produção cartográfica necessária para realizar as análises.

O desenvolvimento do método apresentado permite a utilização de diferentes dimensões e objetos interventores (torres de alturas diferentes ou outros elementos antrópicos), bem como a utilização de outros elementos históricos, paisagísticos e/ou arqueológicos como ponto de partida.

É recomendada a reprodução do método em diferentes cenários, bem como em áreas com relevos e aspetos diferenciados da natureza para validação de resultados, principalmente em relação ao alcance visual na forma logarítmica. 


\section{Referências bibliográficas}

ABATI, S., CELESTINO, V. S.; KUNZ, R. Complexo de PCH do rio pelotinhas - estudo de visibilidade: análise de intervenção na paisagem. Trabalho Técnico. Florianópolis/SC. Eletrosul. 2010. 147 p.

BIBLIOTECA VIRTUAL EM SAÚDE. Disponível em:

<http://regional.bvsalud.org/php/decsws.php?tree_id=G14.760\&lang=PT> Acesso em 05/07/2010.

BISHOP, I. D.; HULSE, D. W. Prediction of scenic beauty using mapped data and geographic information systems. Landscape and Urban Planning, 1994 (30). p. 59 - 70.

CANDEIAS, A.L.B.; TAVARES JÚNIOR, J.R. Cartografia e Realidade Virtual. III Simpósio Brasileiro de Ciências Geodésicas e Tecnologias da Geoinformação - II SIMGEO. Recife - PE. 2008.

CARLSON, A. A. On the possibility of quantifying scenic beauty. Landscape Planning. 1997 (4). p. 131 - 172.

CARMONA, F. M. M.; COSTA, M. F.; VENTURA, D. F.; SALOMÃO, S. R.; BARROS, P. S. M. Acuidade visual de resolução de grades pelo método dos potenciais visuais evocados de varredura: padronização da metodologia para uso em cães. Braz. J. vet. Res. anim. Sci., São Paulo, v. 43, suplemento. 2006. p. 86 - 92.

CELESTINO, V. S. ; KUNZ, R ; ABATI, S. Estudo de visibilidade análise de intervenção na paisagem estudo de caso na Coxilha Rica, Lages/SC. In: XXIV Congresso Brasileiro de Cartografia e II Congresso Brasileiro de Geoprocessamento, 2010, Aracaju/SE. Anais do XXIV Congresso Brasileiro de Cartografia, 2010. v. 1.

ESPARTEL, L. Curso de Topografia. Editora Globo. 1965.

GAZZANIGA, M.S.; IVRY, R.B. \& MANGUN, G.R.. Attention and selective perception. EM: GAZZANIGA M.S.; IVRY, R.B. \& MANGUN, G.R. Cognitive Neuroscience. New York: W.W. Norton \& Company. 1998. p. 207 - 245.

HERBERTS, A. L. Arqueologia do Caminho das Tropas: Estudo das estruturas viárias remanescentes entre os rios Pelotas e Canoas, SC. Porto Alegre. Tese. Doutorado em História, Programa de Pós Graduação em História PPGH. Pontifícia Universidade Católica do Rio Grande do Sul - PUCRS. Porto Alegre. 2009. 170 f.

JENSEN, J. R. Sensoriamento Remoto do Ambiente: uma perspectiva em Recursos Terrestres. Traduação de J. C. N. Epiphanio. São José dos Campos, SP: Parênteses, 2009. 598 p.

LIMA, S. F. C. A função social do espaço penitenciário. Dissertação. Mestrado em arquitetura e urbanismo, Programa de Pós-graduação em Dinâmicas do Espaço Habitado - DEHA. Universidade Federal de Alagoas UFAL. Alagoas. 2004. $157 \mathrm{f}$.

MCBURNEY, D. H. \& COLLINGS, V. B. Introduction to Sensation/Perception (2 ed). Englewood Clijs, NJ: PrenticeHall. 1984.

MIGUENS, A. P. Noções Sobre Geração, Transmissão, Propagação e Recepção das Ondas Eletromagnéticas e Acústicas. In: Navegação: Ciência e a Arte. Volume III. Diretoria de Hidrografia e Navegação (DHN). Brasília. 2000. p. $1221-2010$.

MOURA, Ana Clara Mourão. Geoprocessamento da Gestão e Planejamento Urbano. Ed. da autora. Belo Horizonte-MG, 2003.

OLIVEIRA L. \& MACHADO L. M. C. P. Percepção, Cognição, Dimensão Ambiental e Desenvolvimento com sustentabilidade. In: VITTE A.C. \& GUERRA A. J. T. (orgs.) Reflexões sobre a Geografia Física no Brasil. Rio de Janeiro: Bertrand Brasil, 2004.

RIGGS, L. A. Vision. In McGraw Hill Encyclopedia of Science and Technology (14). New York: McGraw Hill Book Company. 1971.

SCHIFF, W. Perception: An Applied Approach. Boston: Houghton Mifflin Company. 1980. p. 194 - 198.

SELKURT, E. E. Physiology. Boston: Little, Brown and Co. 1961.

SHANG, H.; BISHOP, I. D. Visual thresholds for detection, recognition and visual impact In landscape setting. Journal of Environmental Psycology, 2000 (20). p. $125-140$. 
SILVA, J. L. Nivelamento Trigonométrico. Apostila. UFRGS. 2010. Disponível em: www.ufrgs.br/igeo/departamentos/.../Nivelamento_Trigonometrico.pdf. Acesso: 18 de março de 2010.

SMARDON, R. C.; FEIMER, N. R.; CRAIK, K. H. \& SHEPPARD, S. R. J. Assessing the reliability, validity and generalizability of observer based visual impact assessment methods for Western United States. In R. D. Rowe \& L. G. Chestnut, (Eds), Managing Air Quality and Scenic Resources at National Parks and Wilderness Areas. Boulder, CO: Westview Press. 1983. p. 84 - 102.

STOLFI, G. Percepção Visual Humana. Televisão Digital. 2008.

UNESCO. Convenção do Patrimônio Mundial, 1999. IPHAN. Cartas Patrimoniais. Disponível em: http://unesdoc.unesco.org/images/0013/001333/133369por.pdf. Acesso em: 23 mar. 2009.

WIKIPEDIA. https://pt.wikipedia.org/wiki/Torre de transmiss\%C3\%A3o. Acesso em: 05 jan. 2017. 
Tabela - Determinação da Acuidade Linear

\begin{tabular}{|c|c|c|c|c|c|c|c|c|c|c|c|}
\hline $\mathbf{N}$ & $\mathrm{DH}_{\mathrm{i}}(\mathrm{m})$ & $G_{i}(m)$ & $H_{i}(m)$ & $h_{i}(m)$ & $h_{i(I n)}(m)$ & $\mathbf{N}$ & $\mathrm{DH}_{\mathrm{i}}(\mathrm{m})$ & $G_{i}(m)$ & $H_{i}(m)$ & $h_{i}(m)$ & $h_{i(I n)}(m)$ \\
\hline 1 & 100 & 0,0007 & 23,9993 & 1,4635 & 1,2697 & 51 & 5100 & 1,7762 & 22,2238 & 0,0266 & 0,0229 \\
\hline 2 & 200 & 0,0027 & 23,9973 & 0,7317 & 0,6348 & 52 & 5200 & 1,8465 & 22,1535 & 0,0260 & 0,0223 \\
\hline 3 & 300 & 0,0061 & 23,9939 & 0,4877 & 0,4231 & 53 & 5300 & 1,9182 & 22,0818 & 0,0254 & 0,0218 \\
\hline 4 & 400 & 0,0109 & 23,9891 & 0,3657 & 0,3173 & 54 & 5400 & 1,9913 & 22,0087 & 0,0249 & 0,0214 \\
\hline 5 & 500 & 0,0171 & 23,9829 & 0,2925 & 0,2537 & 55 & 5500 & 2,0657 & 21,9343 & 0,0243 & 0,0209 \\
\hline 6 & 600 & 0,0246 & 23,9754 & 0,2437 & 0,2114 & 56 & 5600 & 2,1415 & 21,8585 & 0,0238 & 0,0204 \\
\hline 7 & 700 & 0,0335 & 23,9665 & 0,2088 & 0,1811 & 57 & 5700 & 2,2187 & 21,7813 & 0,0233 & 0,0200 \\
\hline 8 & 800 & 0,0437 & 23,9563 & 0,1826 & 0,1584 & 58 & 5800 & 2,2972 & 21,7028 & 0,0228 & 0,0196 \\
\hline 9 & 900 & 0,0553 & 23,9447 & 0,1622 & 0,1407 & 59 & 5900 & 2,3771 & 21,6229 & 0,0223 & 0,0192 \\
\hline 10 & 1000 & 0,0683 & 23,9317 & 0,1459 & 0,1266 & 60 & 6000 & 2,4584 & 21,5416 & 0,0219 & 0,0188 \\
\hline 11 & 1100 & 0,0826 & 23,9174 & 0,1326 & 0,1150 & 61 & 6100 & 2,5410 & 21,4590 & 0,0215 & 0,0184 \\
\hline 12 & 1200 & 0,0983 & 23,9017 & 0,1215 & 0,1053 & 62 & 6200 & 2,6250 & 21,3750 & 0,0210 & 0,0180 \\
\hline 13 & 1300 & 0,1154 & 23,8846 & 0,1120 & 0,0972 & 63 & 6300 & 2,7104 & 21,2896 & 0,0206 & 0,0176 \\
\hline 14 & 1400 & 0,1338 & 23,8662 & 0,1040 & 0,0901 & 64 & 6400 & 2,7971 & 21,2029 & 0,0202 & 0,0173 \\
\hline 15 & 1500 & 0,1536 & 23,8464 & 0,0969 & 0,0840 & 65 & 6500 & 2,8852 & 21,1148 & 0,0198 & 0,0169 \\
\hline 16 & 1600 & 0,1748 & 23,8252 & 0,0908 & 0,0787 & 66 & 6600 & 2,9747 & 21,0253 & 0,0194 & 0,0166 \\
\hline 17 & 1700 & 0,1974 & 23,8026 & 0,0854 & 0,0740 & 67 & 6700 & 3,0655 & 20,9345 & 0,0191 & 0,0163 \\
\hline 18 & 1800 & 0,2213 & 23,7787 & 0,0806 & 0,0698 & 68 & 6800 & 3,1577 & 20,8423 & 0,0187 & 0,0160 \\
\hline 19 & 1900 & 0,2465 & 23,7535 & 0,0762 & 0,0661 & 69 & 6900 & 3,2512 & 20,7488 & 0,0183 & 0,0157 \\
\hline 20 & 2000 & 0,2732 & 23,7268 & 0,0723 & 0,0627 & 70 & 7000 & 3,3462 & 20,6538 & 0,0180 & 0,0154 \\
\hline 21 & 2100 & 0,3012 & 23,6988 & 0,0688 & 0,0596 & 71 & 7100 & 3,4424 & 20,5576 & 0,0177 & 0,0151 \\
\hline 22 & 2200 & 0,3305 & 23,6695 & 0,0656 & 0,0568 & 72 & 7200 & 3,5401 & 20,4599 & 0,0173 & 0,0148 \\
\hline 23 & 2300 & 0,3612 & 23,6388 & 0,0627 & 0,0543 & 73 & 7300 & 3,6391 & 20,3609 & 0,0170 & 0,0145 \\
\hline 24 & 2400 & 0,3933 & 23,6067 & 0,0600 & 0,0519 & 74 & 7400 & 3,7395 & 20,2605 & 0,0167 & 0,0142 \\
\hline 25 & 2500 & 0,4268 & 23,5732 & 0,0575 & 0,0498 & 75 & 7500 & 3,8412 & 20,1588 & 0,0164 & 0,0139 \\
\hline 26 & 2600 & 0,4616 & 23,5384 & 0,0552 & 0,0478 & 76 & 7600 & 3,9444 & 20,0556 & 0,0161 & 0,0137 \\
\hline 27 & 2700 & 0,4978 & 23,5022 & 0,0531 & 0,0459 & 77 & 7700 & 4,0488 & 19,9512 & 0,0158 & 0,0134 \\
\hline 28 & 2800 & 0,5354 & 23,4646 & 0,0511 & 0,0442 & 78 & 7800 & 4,1547 & 19,8453 & 0,0155 & 0,0132 \\
\hline 29 & 2900 & 0,5743 & 23,4257 & 0,0493 & 0,0426 & 79 & 7900 & 4,2619 & 19,7381 & 0,0152 & 0,0129 \\
\hline 30 & 3000 & 0,6146 & 23,3854 & 0,0475 & 0,0411 & 80 & 8000 & 4,3705 & 19,6295 & 0,0150 & 0,0127 \\
\hline 31 & 3100 & 0,6563 & 23,3437 & 0,0459 & 0,0397 & 81 & 8100 & 4,4804 & 19,5196 & 0,0147 & 0,0125 \\
\hline 32 & 3200 & 0,6993 & 23,3007 & 0,0444 & 0,0384 & 82 & 8200 & 4,5917 & 19,4083 & 0,0144 & 0,0122 \\
\hline 33 & 3300 & 0,7437 & 23,2563 & 0,0430 & 0,0372 & 83 & 8300 & 4,7044 & 19,2956 & 0,0142 & 0,0120 \\
\hline 34 & 3400 & 0,7894 & 23,2106 & 0,0416 & 0,0360 & 84 & 8400 & 4,8185 & 19,1815 & 0,0139 & 0,0118 \\
\hline 35 & 3500 & 0,8365 & 23,1635 & 0,0404 & 0,0349 & 85 & 8500 & 4,9339 & 19,0661 & 0,0137 & 0,0116 \\
\hline 36 & 3600 & 0,8850 & 23,1150 & 0,0392 & 0,0338 & 86 & 8600 & 5,0506 & 18,9494 & 0,0134 & 0,0114 \\
\hline 37 & 3700 & 0,9349 & 23,0651 & 0,0380 & 0,0328 & 87 & 8700 & 5,1688 & 18,8312 & 0,0132 & 0,0111 \\
\hline 38 & 3800 & 0,9861 & 23,0139 & 0,0369 & 0,0319 & 88 & 8800 & 5,2883 & 18,7117 & 0,0130 & 0,0109 \\
\hline 39 & 3900 & 1,0387 & 22,9613 & 0,0359 & 0,0310 & 89 & 8900 & 5,4092 & 18,5908 & 0,0127 & 0,0107 \\
\hline 40 & 4000 & 1,0926 & 22,9074 & 0,0349 & 0,0301 & 90 & 9000 & 5,5314 & 18,4686 & 0,0125 & 0,0105 \\
\hline 41 & 4100 & 1,1479 & 22,8521 & 0,0340 & 0,0293 & 91 & 9100 & 5,6550 & 18,3450 & 0,0123 & 0,0103 \\
\hline 42 & 4200 & 1,2046 & 22,7954 & 0,0331 & 0,0286 & 92 & 9200 & 5,7800 & 18,2200 & 0,0121 & 0,0102 \\
\hline 43 & 4300 & 1,2627 & 22,7373 & 0,0322 & 0,0278 & 93 & 9300 & 5,9063 & 18,0937 & 0,0119 & 0,0100 \\
\hline 44 & 4400 & 1,3221 & 22,6779 & 0,0314 & 0,0271 & 94 & 9400 & 6,0340 & 17,9660 & 0,0117 & 0,0098 \\
\hline 45 & 4500 & 1,3828 & 22,6172 & 0,0306 & 0,0264 & 95 & 9500 & 6,1631 & 17,8369 & 0,0114 & 0,0096 \\
\hline 46 & 4600 & 1,4450 & 22,5550 & 0,0299 & 0,0258 & 96 & 9600 & 6,2935 & 17,7065 & 0,0112 & 0,0094 \\
\hline 47 & 4700 & 1,5085 & 22,4915 & 0,0292 & 0,0251 & 97 & 9700 & 6,4253 & 17,5747 & 0,0110 & 0,0092 \\
\hline 48 & 4800 & 1,5734 & 22,4266 & 0,0285 & 0,0245 & 98 & 9800 & 6,5585 & 17,4415 & 0,0109 & 0,0091 \\
\hline 49 & 4900 & 1,6396 & 22,3604 & 0,0278 & 0,0240 & 99 & 9900 & 6,6930 & 17,3070 & 0,0107 & 0,0089 \\
\hline 50 & 5000 & 1,7072 & 22,2928 & 0,0272 & 0,0234 & 100 & 10000 & 6,8289 & 17,1711 & 0,0105 & 0,0087 \\
\hline
\end{tabular}

